\title{
Vozes em duelo: notas sobre a cultura italiana do ventennio mussoliniano
}

\author{
Gaspare Trapani \\ Universidade Católica Portuguesa \\ ergogaspare@hotmail.com
}

\section{Resumo:}

O presente artigo tem como objetivo analisar a relação entre o regime fascista de Mussolini e a cultura produzida durante os vinte anos de poder do Duce, tendo em consideração quer a cultura e os intelectuais que o apoiaram, quer a cultura e os representantes da oposição que, apesar da censura, refletiram sobre esses anos da ditadura italiana. De fato se, por um lado, oregime fascista tentou controlar, também a nível cultural, o conjunto da sociedade italiana com o objetivo de construir uma sólida base de apoio, através de homens de confiança a quem Mussolini atribuiu as funções culturais mais importantes, através dos meios de comunicação de massa e de intelectuais "fascistizzati", por outro lado, a oposição lutando contra a censura, introduzida pelo regime, estava na vanguarda de uma batalha feroz contra o fascismo.

Palavras-chave: Mussolini. Fascismo. Cultura. Neorrealismo. Censura.

\section{Abstract:}

L'articolo che qui si presenta ha come obiettivo quello di analizzare il rapporto tra il regime fascista di Mussolini e la cultura prodotta nel corso dei venti anni di potere del Duce, prendendo in considerazione sia la cultura che gli intellettuali che l'hanno appoggiato, sia la cultura e i rappresentanti dell'opposizione che, nonostante la censura, effettuarono una riflessione su questi anni di dittatura italiana. In effetti, se per un verso il regime fascista cercò di controllare, anche a livello culturale, l'insieme della società italiana con l'obiettivo di costruire una solida base d'appoggio, tramite uomini di 
fiducia a cui Mussolini attribuì i ruoli culturali più importanti, mediante mezzi di comunicazione di massa ed intellettuali "fascistizzati", per l'altro, l'opposizione, in continua lotta con la censura, capeggiava una feroce battaglia contro il fascismo.

Parole-chiave: Mussolini.Fascismo. Cultura. Neorealismo.Censura.

\section{Abstract:}

This article aims to analyze the relationship between the fascist regime of Mussolini and the culture produced during the twenty years of power of the Duce, taking into account both the culture and intellectuals who supported both the culture and the representatives of the opposition that despite censorship reflected on the years during the Italian dictatorship. Indeed, on the one hand, the fascist regime tried to control also in the cultural level the whole of Italian society in order to build a solid base of support through trusted men whom Mussolini attributed the most important cultural functions through the mass media and intellectuals "fascistizzati", on the other hand, there was the opposition fighting against censorship introduced by the regime which was at the forefront of a fierce battle against fascism .

Keywords: Mussolini. Fascism. Culture. Neorealism. Censorship.

\section{Introdução}

"Signori! Mi sono rifiutato di stravincere e potevo stravincere. Mi sono imposto dei limiti. Mi sono detto che la migliore saggezza è quella che non vi abbandona dopo la vittoria" (MUSSOLINI, 1934: 36). São estas as palavras pronunciadas por Mussolini num discurso ao Parlamento, em 16 de Novembro de 1922, poucas semanas depois da Marcia su Roma que, em 27 de Outubro do mesmo ano, dá início ao regime fascista em Itália. 


\section{Gaspare Trapani}

"Per il fascista, tutto è nello Stato, e nulla di umano e spirituale esiste, e tanto meno ha valore, fuori dallo Stato. In tal senso il fascismo è totalitário, e lo Stato Fascista, sintesi e unità di ogni valore, interpreta, sviluppa e potenzia tutta la vita di un popolo" (MUSSOLINI, 1934, p. 71). Com estas palavras, proferidas em 1930, Mussolini anuncia a fascistizzaz̧ione da Nação, ou seja a identificação total do fascismo com o Estado; é assim que este se dota de um eficiente aparelho que garante, por um lado, a consolidação do consenso e por outro, o controlo do mesmo. A cultura torna-se, portanto, um instrumento fundamental quer nas mãos dos fascistas, quer nas mãos da oposição, para alargar ou mesmo controlar o consenso - no caso dos fascistas - e, para denunciar ou doutrinar, no caso das oposições.

\subsection{A voz do regime}

Suprimida, em 1925, qualquer manifestação de vida democrática, obrigada a oposição ao exílio ou à expatriação ou, pior ainda, ao silêncio da prisão, Mussolini tenta atar a cultura ao carro do regime.

As leis fascistissime atingem, de fato, também a cultura, com a abolição da liberdade de imprensa e a introdução da censura até o controlo total efetuado pelo Ministero della Cultura Popolare.

À supressão das livres actividades culturais, o fascismo tentou responder com a afirmação de uma cultura que refletisse a ideologia e a política do regime, mas nem sempre, como afirma num ensaio o filósofo Norberto Bobbio, os resultados foram de grande nível:

Una cultura fascista nel duplice senso di fatta da fascisti dichiarati o a contenuto fascista, non è mai realmente esistita, $\mathrm{o}$ almeno non riuscì mai, per quanti sforzi venissero compiuti, a prender forma in iniziative o imprese durature e storicamente rilevanti. L'unico gruppo che tentò di elaborare una dottrina originale e cercò di non perdere i contatti col resto 


\section{Gaspare Trapani}

del mondo, fu quello dei giovani gentiliani ${ }^{1}$ che si raccolsero intorno a Bottai²nella scuola di scienze corporative dell'Università di Pisa. Ma durò poco $[\ldots]$ per il resto gli intellettuali integralmente fascisti - dico 'integralmente' per distinguerli da tutti coloro che erano fascisti solo in quel quarto d'ora in cui scrivevano su una rivista fascista o facevano una dichiarazione d'omaggio al duce, insomma gli opportunisti, con la fede 'a comodo', e furono la stragrande maggioranza - erano intellettuali di mezza tacca. (BOBBIO, 1973, p. 97).

Com efeito, sobre a influência negativa que o regime fascista teve relativamente à vida cultural e literária, discutiu-se amplamente logo depois da queda de Mussolini. Entre as opiniões parece interessante a do poeta Eugenio Montale, prémio Nobel pela literatura em 1975, que, em abril de 1945, logo depois da libertação, disse:

Nessuna traccia positiva, nessuna opera o figura degna di rilievo lascia il fascismo alle nostre lettere, anche se qualcosa, anzi molto ha tentato di fare o di distruggere [...] Nessuno scrittore di rilievo ne venne fuori, nessuna pagina degna di ricordo fu rivelata.(MONTALE, 1966,p. 20-21).

Efetivamente, os intelectuais que inicialmente apoiaram os movimentos de direita - Gabriele D’Annunzio e Filippo Tommaso Marinetti, para citar os mais ilustres - foram rapidamente afastados pelo regime, sendo considerados revolucionários incomodos.

O próprio Duce, de resto, sabia perfeitamente que a nova ordem política por ele implementada precisava de uma literatura original e significativa para nobilitar as origens, o alcance e as razões desta mesma revolução. Fascismo devia também implicar uma vida nova nas artes e nas letras. Era necessária, portanto, uma literatura que fosse o espelho da nova Itália: “Occorreva perciò

\footnotetext{
${ }^{1}$ A referência aqui é a Giovanni Gentile, filósofo e homem politico siciliano. Foi Ministro da Educação. Amigo e, logo depois, adversário de Benedetto Croce, elaborou em 1925 o Manifesto degli intellettuali fascisti. No mesmo ano Croce respondeu com o Manifesto degli intellettuali antifascisti.

${ }^{2}$ Homem politico fascista que participou também na Marcia su Roma. Foi Ministro da Educação, depois de Giovanni Gentile, e a ele se deve a Carta della scuola, um documento que reformava a escola do ponto de vista fascista.
} 


\section{Gaspare Trapani}

una letteratura costruttiva, romana, imperiale, che incidesse nel bronzo i segni del tempo di Mussolini” (MONTALE, 1966,p. 21).

Daí os temas fundamentais das obras publicadas deviam ser: a exaltação da pátria, da família, do trabalho, a fecundidade e a maternidade das mulheres, as tradições históricas italianas, o trabalho dos italianos no estrangeiro, a ambivalência primitiva do fascismo de uma alma nacional-camponesa e de uma Itália rural e católica contraposta àquela europeia-industrial, o tema da "romanidade", o motivo colonial ou da guerra, o erotismo, numa série de romances que não deixaram marca depois da queda do fascismo.

Desta forma, as principais revistas literárias fascistas (LUTI, 1995), Critica Fascista, Il Selvaggio, l'Italiano, Primato, funcionavam como alto-falantes do regime, sendo, de fato, uma síntese dos propósitos e dos percursos da cultura e da era fascista e revelando, todavia, um nível qualitativo bastante baixo "il fascismo temendo le descrizioni e le rappresentazioni dirette della realtà, aveva contribuito a spostare l'asse letterario verso le sponde tradizionali dell'astrazione retorica e dell'evasione.” (BO, 1975, p. 398).

Mais uma vez Montale observa: "Il fascismo non aveva saputo creare una sua verità, ma aveva gravemente scalzato la verità di sempre, la verità che è nascosta nel cuore di tutti e che attende di essere riscoperta di generazione in generazione" (MONTALE, 1966, p. 23).

Vale a pena mencionar que, naqueles anos, o livro mais comprado foi "Mussolini”" uma biografia de Giorgio Pini, que, em 15 anos, vendeu 400.000 cópias.

O próprio Mussolini, de resto, gostava muito de alimentar, junto do povo, a sua imagem de homem culto e letrado, considerando a cultura uma área fundamental para a vida nacional e a consolidação do regime. Por isso amava, não só rodear-se de intelectuais e artistas, mas também reproduzir um ideal de 
um artista diletante, de uma pessoa erudita, mesmo que dedicada a outros setores da vida pública.

Muito curioso é o fato de ele ter sido o coautor do drama teatral Campo di Maggio, que estreou, no dia 20 de dezembro de 1930, no Teatro Argentina em Roma. Na realidade o único nome que aparecia na autoria da peça era o de Giovacchino Forzano: por razões de tempo e de oportunismo político, Mussolini não quis escrever pessoalmente o drama, delegando a sua redação a um profissional como Forzano, famoso jornalista e autor de dramas históricos e livretes de óperas (de Puccini e Mascagni, entre os outros). Forzano, porém, escreveu a peça seguindo as instruções do Duce. Campo di Maggio, que narra os cem dias de Napoleão e o episódio de Waterloo, foi um grande sucesso que também os jornais registaram, sem nunca citar o nome de Mussolini. Depois de uma triunfal etapa em Milão, o drama foi apresentado no estrangeiro e é curioso que aqui o ditador, permitiu que o seu nome aparecesse, entre os autores, ao lado do de Forzano.

O êxito da colaboração com o jornalista encorajou Mussolini a continuar a sua parceria com Forzano. Assim, em 1931 foi pronta a peça Villafranca, inspirada na figura de Cavour e, nestes mesmos anos, as duas peças foram transferidas para o grande ecrã, em dois filmes dirigidos pelo mesmo Forzano.

Em 1939, foi apresentado ao público Giulio Cesare. Giovacchino Forzano mostrou-se entusiasmado com a leitura do projeto desta última peça e não hesitou a escrevê-lo numa carta dirigida ao próprio Duce: "sono due giorni che studio il Suo Cesare e sento il desiderio di dirLe tutta la mia ammirazione; è una sintesi superba per chiarezza ed efficacia..." (SCARPELLINI, 2006, p. 27).

Tratava-se, mais uma vez, de uma peça protagonizada por uma importante figura histórica. Não é difícil estabelecer uma comparação entre as personagens principais destas peças - Napoleão, Cavour e César - e o mesmo 
Duce: Mussolini olhava para eles como modelos de referência, pensando, talvez, de se pôr simbolicamente e historicamente ao lado deles, como herói nacional.

Mas porque Mussolini preferiu, pelo menos em Itália, que o seu nome ficasse na sombra? Uma possível explicação desta atitude é que provavelmente Mussolini, em Itália temia comentários irreverentes, enquanto que, no estrangeiro, ele podia aumentar o seu prestígio, sendo reconhecido também como um apreciado autor de teatro. Significativos são, para este propósito, as instruções que foram enviadas aos jornais em 1934:

Il Corriere della Sera ha annunciato come imminente una rappresentazione di 'Giulio Cesare di Mussolini e Forzano'. Va osservato, in primo luogo, che ancora il dramma non è pronto e che poi - e questo vale come regola di massima - il nome di Mussolini non va assolutamente trattato così; non si può unire un nome simile ad un altro come se si trattasse di due qualsiasi commediografi. Quando e se l'opera sarà compiuta bisognerà dire 'Giulio Cesare di Forzano su trama di Mussolini'. (SCARPELLINI, 2006, p. 27).

\subsection{A voz da oposição cultural.}

Dentro deste contexto cultural extremamente controverso, é possível distinguir dois tipos de atitudes dos intelectuais da época: uma de oposição ao regime e a outra de quem, de uma certa forma, defende e apoia as palavras de ordem fascistas. Muitas vezes estes dois caminhos confundem-se, como aconteceu no caso de Luigi Pirandello. O dramaturgo siciliano viu, inicialmente, no fascismo uma saída à crise italiana mas, logo depois do assassinato de Matteotti, não hesitou a reivindicar com força a sua autonomia de artista com uma frase iluminante:

La mia vita non è che lavoro e studio [...] sono isolato dal mondo e non ho che il mio lavoro e la mia arte. La politica? Non me ne occupo, non me ne sono mai occupato. Se alludete al mio recente atto di adesione al fascismo, vi diro che è stato compiuto allo scopo di aiutare il fascismo 


\section{Gaspare Trapani}

nella sua opera di rinnovamento e di ricostruzione. (HAMILTON, 1972, p. 62)

E de fato, não se pode negar que toda a sua arte fale uma língua diferente da do fascismo (BORSELLINO, 1991).

A cultura da época fascista aparece, portanto, como um território extremamente rico e vário, onde podia viver "tranquilamente" apenas quem acreditava ou "tolerava" os ideais fascistas, utilizando-os como uma espécie de "carta de condução" que permitia o livre movimento nesse mesmo território. Afirmava-se, portanto, o chamado fascismo di toga, ou seja uma fascização também na área cultural:

Bastò allora, per esser detto scrittore fascista, l'aperta adesione al regime o meglio ancora qualche esplicita piaggeria al suo fondatore [...] Sicché fu presto ammesso che scrittori fascisti (i soli, per esempio, ai quali potessero toccare premi letterari) erano gli scrittori tesserati; e scrittori antifascisti o afascisti, i pochi altri ch'erano rimasti fuori dal partito. (MONTALE, 1966,p. 22).

Muito mais complicado era, por conseguinte, agir no outro lado. Gaetano Salvemini observa a este propósito:

La libertà è per me intellettuale che scrivo queste pagine, il diritto di esporre le mie opinioni politiche, sociali, religiose, economiche, senza vedere la mia casa invasa come quella di Croce, senza vedere i miei libri buttati dalla finestra nella strada come quelli di $\mathrm{Bracco}^{3}$, senza essere sottomesso alla sorveglianza speciale come Ferrero ${ }^{4}$, senza essere mandato alle isole come Parri e Rosselli, senza essere costretto a lasciare l'Italia come Nitti, Turati, don Sturzo [...]. (SALVEMINI, 1988, p. 476).

Neste contexto, muito interessante foi a experiência da revista romana $L a$ Ronda, ponto de referência para os numerosos literatos antifascistas da época. Surgida em 1919, ao longo de quatro anos foi constituída por um núcleo de

\footnotetext{
${ }^{3}$ O dramaturgo napolitano Roberto Bracco.

${ }^{4}$ Guglielmo Ferrero, historiador e sociólogo napolitano mas falecido na Suiça, em exílio.
} 
intelectuais que, afastando-se da dimensão política e social da época, se isolava na própria actividade artística.

A sua experiência foi continuada pela revista Solaria, cuja existência foi, muitas vezes, obstaculizada por proibições e censuras. Fundada em 1926, teve, entre os seus colaboradores, literatos como Eugenio Montale, Umberto Saba e Elio Vittorini. Como em La Ronda, não houve uma tomada de atitude firme contra o fascismo, mas a revista marcou, de qualquer forma, do ponto de vista literário, uma passagem da prosa de arte ao romance como interpretação do tempo e da sociedade, numa tendência contrária a "evanescente" literatura “oficial" fascista. O fundador da revista, Alberto Carocci, falando de Solaria admite:

Essa non rappresentò una presa di posizione completa e coerente di fronte all'ambiente, alla cultura agli eventi storici entro i quali si trovò a operare: fu essa estessa l'espressione di una piccola polis letteraria, una società in nuce con tutte le sue contraddizioni interne, i suoi dubbi, le sue esitazioni, col prevalere di volta in volta di istanze contrastanti [...] Essa, molto più modestamente, e con l'accettare l'isolamento in cui la letteratura ufficiale la relegava (i lettori di Solaria furono sempre quattro gatti; la sua tiratura non raggiungeva le 700 copie; né ricordo che essa ricevesse mai l'onore di esser citata dai giornali del tempo) svolse tutt'al più una funzione di obiettore di coscienza .(SICILIANO, 1958, p. 9-10).

Outro grande mérito da revista foi o de ter introduzido em Itália um discurso literário de tipo europeu:

[...] la Francia che compare nelle pagine di Solaria sarà ora sì quella di Valéry e di Proust, ma anche quella della Vie royale e della Condition Humaine di Malraux, delle Pages de Journal di Gide; e la Russia sarà quella di Majakovskij e l'Inghilterra avrà voce nelle pagine di Dedalus e dei Dubliners (di Joyce), e la Germania apparirà nella tragica ironia del soldato di Zweig e nella coscienza narrativa di Mann. (LUTI, 1966, p. 90).

Parece quase que a literatura está timidamente a tomar consciência da realidade andando na justa direção, mesmo que no meio daquela angústia política. Solaria abre, assim, uma esperança: 


\section{Gaspare Trapani}

L'orizzonte si è aperto: sia pure nel limitato cielo solariano e per un attimo solo. Ma il primo seme è gettato e non è certo un caso se nelle Edizioni di Solaria appare il primo libro di Pavese, quel Lavorare stanca che tanta importanza dovrà assumere per la generazione che uscirà dalla guerra. (LUTI, 1966,p. 91).

Para muitos intelectuais, de fato, à medida que o tempo passava, o fascismo "agì da antidoto su una parte della cultura italiana, idealmente guidata da Benedetto Croce, non tanto quella letteraria, quanto quella storica e filosofica, e la indusse all'impegno politico contro la dittatura" (CAROCCI, 1998, p. 301).

Benedetto Croce, assim, denunciava de uma forma explícita nos seus ensaios históricos: Storia d'Italia (1928), Storia d'Europa nel secolo XIX (1932) e Storia come pensiero e come azione (1938) a ditadura, manifestando abertamente a sua oposição.

Ao mesmo tempo, o marxismo registrava, através essencialmente da figura de Engels, uma posição que, em conformidade com os princípios do materialismo histórico, mirava a identificar a arte com o realismo, dando-lhe, assim, a finalidade de reproduzir os caracteres típicos da realidade. Algum tempo depois, Lukáks, aprofundando melhor os problemas da arte e da crítica literária, dirá que a única forma de arte é o realismo, não como mera e passiva reprodução da realidade nos seus aspectos diários e superficiais, mas sim como representação da totalidade da vida humana no seu movimento, no seu desenvolvimento e na sua evolução. A cultura marxista, contudo, foi completamente excomungada pelo regime e os cadernos que Gramsci escreveu aquando da sua prisão, entre 1929 e 1934, só foram publicados depois da queda do fascismo.

Outra figura importante da época foi Piero Gobetti. Em Turim, um dos mais activos centros culturais da época, funda, primeiro a revista Rivoluqione liberale, e depois, em 1924, Il Baretti que, em luta contra o irracionalismo da 


\section{Gaspare Trapani}

cultura fascista e do formalismo evasivo dos rondistas, opta por uma renovação da consciência do intelectual italiano e por uma cultura mais fixada nos problemas da sociedade: "Un compito tecnico preciso ci attende: la preparazione degli spiriti liberi, capaci di aderire fuori dai pregiudizi, nel momento risolutivo, all'iniziativa popolare" (GOBETTI, 1960, p. 240).

E a importância destas figuras, Gramsci e Gobetti, ambos de Turim, é sublinhada também por Montale que os define: "scrittori d'azione e non artisti, che seppero indicarci con l'opera e con l'esempio la via che deve seguire un italiano universale, cioè un italiano di sempre, nelle ore dell'oscuramento e dell'errore" (MONTALE, 1966, p. 23).

O exemplo destas personalidades não foi, de fato, em vão: nascia, com efeito, nos intelectuais, uma vontade de "angariar" um público novo numa opção alternativa ou mesmo contrária à dos rondistas que desdenhavam preocupar-se com o que acontecia ao povo, preferindo escrever para um público selecionado de entendidos, maioritariamente burguês.

Uma obra, considerada de viragem, na literatura italiana destes anos é Gli Indifferenti,que Alberto Moravia publicou em 1929, um romance que desagradou à crítica fascista. Gli Indifferenti é o primeiro romance que, pela sua índole moral, se opõe claramente ao clima literário dominante durante o fascismo; o tema fundamental é a indiferença, a atitude de não tomar posição, a abulia relativamente a questões que pedem a coragem da ação, uma angústia existencial, uma espécie de nausée, como, alguns anos mais tarde, em 1938 diria Sartre.

Um ano depois, Gente in Aspromonte de Corrado Alvaro, contrastando com a retórica patriótica e obstinadamente nacionalista daqueles anos, abre o caminho para uma literatura de inquérito sobre o mundo meridional italiano.

Estes dois romances e, em seguida, as obras de Ignazio Silone, Beppe Fenoglio, Francesco Jovine, Carlo Bernari, podem ser considerados sinais de 


\section{Gaspare Trapani}

uma renovação das consciências da época e de uma inédita figura de intelectual.

De resto, mesmo dentro do ambiente cultural fascista, alguma coisa mudava. Em 1933, de fato, a revista L'Universale publicava o Manifesto realista, que chamava a cultura italiana a dar o próprio contributo para a revolução fascista, um contributo antiburguês, anticapitalístico de autonomia dentro do fascismo, em nome da cultura popular e do espírito reivindicativo do "primeiro fascismo".

Outro ano crucial é 1936: o fascismo está no seu apogeu porque vence a Guerra d'Africa e participa diretamente na expansão e propagação dos regimes reacionários na Europa, a Espanha de Franco, em primeiro lugar. É nesse contexto que amadurece uma mudança substancial da perspectiva ideológica: "in Italia si inizia un'opposizione giovanile assai interessante, e militanti comunisti cominciano un nuovo tipo di attività, facendo sentire parole nuove, nell'ambito di alcune strutture di per sé più inquiete e portate alla ricerca del nuovo" (FALASCHI, 1977, p. 19).

Esta polemica pública acaba por constituir um afloramento da luta ideológica que vinha sendo desenvolvida pelo Partido Comunista - ao qual a grande maioria dos intelectuais da oposição da época eram inscritos - em condições particularmente difíceis, dada a grande pressão policial e a enorme campanha ideológica conduzida pelo regime de Mussolini.

Um contributo notável foi dado por Elio Vittorini e Cesare Pavese partilharam o mérito da descoberta da cultura americana em Itália. O primeiro publicou a antologia Americana, imediatamente sequestrada pela censura, enquanto que Pavese formou-se mesmo em literatura norte-americana, estudando, traduzindo e escrevendo ensaios sobre Whitman, Dos Passos e Melville, entre outros. Ninguém melhor que Pavese conseguiu salientar o 
papel cultural e de oposição antifascista da "descoberta da América", como escreveu num artigo de 1947, publicado em L'Unità:

Verso il 1930, quando il fascismo cominciava a essere 'la speranza del mondo', accadde ad alcuni giovani italiani di scoprire nei suoi libri l'America, una America pensosa e barbarica, felice e rissosa, dissoluta, feconda, greve di tutto il passato del mondo, e insieme giovane, innocente. Per qualche anno questi giovani lessero tradussero e scrissero con una gioia di scoperta e di rivolta che indignò la cultura ufficiale, ma il successo fu tanto che costrinse il regime a tollerare, per salvare la faccia [...] Il regime tollerò a denti stretti, e stava intanto sulla breccia, sempre pronto a profittare di un passo falso, di una pagina più cruda, d'una bestemmia più diretta, per pigliarci sul fatto e menare la botta. (PAVESE, 1951, p. 173).

A Segunda Guerra Mundial é um ulterior choque para os intelectuais que sentem, ainda mais, a necessidade de compreender o "país real", de prestar atenção aos fatos históricos contemporâneos, contra aquela tipologia de intelectuais, fechados numa torre de marfim e perdidos num interminável diálogo consigo próprios, como observa Giame Pintor, jornalista, literato e colaborador da editora Einaudi:

Senza la guerra io sarei rimasto un intellettuale con interessi prevalantemente letterari... A un certo momento gli intellettuali devono essere capaci di trasferire la loro esperienza sul terreno dell'utilità comune, ciascuno deve sapere prendere il suo posto di combattimento... Musicisti e scrittori dobbiamo rinunciare ai nostri privilegi per contribuire alla liberazione di tutti. (PINTOR, 1965, p. 187).

A palavra de ordem, torniamo al reale!, significava uma procura das coisas, dos fatos, das palavras, com que documentar a existência de uma realidade ignorada e reprimida pela cultura e até pela linguagem fascista, ainda por cima contrária ao uso do dialeto que, muitas vezes, era a única língua que o povo conhecia. Foi com estes pressupostos que se começou a falar de Neorrealismo, do alemão "Neue Sachlichkeit", usado a partir de 1926: o crítico Arnaldo Bocelli, foi pioneiro no uso desta designação em Itália, 
indicando, em 1931, uma série de autores e obras literárias que ligavam o humano ao ambiente social.

Em 1942 o realizador Luchino Visconti roda o filme Ossessione, baseado no romance The Postman always Rings Twice de James Cain: foi esta a primeira película da extraordinária estação cinematográfica italiana do pós-guerra que tornou celebre a designação "Neorealismo". O mesmo Visconti refere:

Il termine 'neorealismo' nacque con Ossessione. Fu quando da Ferrara mandai a Roma i primi pezzi del film al mio montatore, che è Mario Serandrei. Dopo alcuni giorni egli mi scrisse esprimendo la sua approvazione per quelle scene. E aggiungeva: 'Non so come potrei definire questo tipo di cinema se non con l'appellativo di neorealistico'. (CORTI, 1978, p. 29).

São duas as novidades dos filmes neorrealistas em relação ao passado: por um lado, um elemento crítico que vê na obra cinematográfica um meio construtivo que não cala os sofrimentos mas os denuncia, tentando, por vezes, encontrar uma esperança de solução; por outro, o elemento testemunhal: o filme neorrealista não é um documentário tout court mas pretende ser um documento, um depoimento histórico. Por estas razões, não se olha para a história individual, mas para a história coletiva: os partigiani, as mulheres abandonadas pelos maridos depois da guerra, os pobres à espera da paz. Com a simplicidade dos meios da época, o Neorrealismo cinematográfico, afirmando-se com alguns dos filmes italianos mais significativos da história do cinema mundial, como Roma città aperta (1945), Sciuscià (1946), Paisà (1947), Ladri di biciclette (1948), La terra trema (1948), usufruiu de um clima cultural e político, o da frente do pós-resistência no qual várias vozes - Rossellini, De Sica para além do já mencionado Visconti frequentemente de origem diversa, encontraram elementos de consonância.

Em âmbito literário, hoje tende-se a distinguir um Neorrealismo anterior à guerra (anos Trinta), como verdadeira literatura de oposição, de tipo conteudístico e anti-formalístico, de um Neorrealismo de pós-guerra (1943- 


\section{Gaspare Trapani}

1950), considerando, portanto, o conflito e a queda do fascismo, como um ponto de partida para uma nova reflexão sobre estes mesmos acontecimentos recentes.

O Neorrealismo, como corrente inovadora da cultura, nas diversas formas de expressão, surge, portanto, num contexto de um processo de mudança histórica de dimensões universais, marcado por contradições profundas: ajuste de contas das duas Guerras Mundiais; o Holocausto, a Bomba Nuclear, uma nova arrumação de forças no Mundo, redistribuição de posições no sistema colonial do imperialismo; surgimento do primeiro Estado Socialista no mundo; implantação e fortalecimento dos regimes fascistas na Europa; primeira grande explosão da Crise Geral do sistema capitalista mundial de 1929; triunfo, expansão e derrota do nazi-fascismo; Guerra Civil Espanhola; Plano Marshall. Como observou sagazmente Shoshana Felman relativamente à fase histórica em questão: "The world has changed more in the past fifty years than it did in the previous two hundred years" (FELMAN, 1992, p. 114).

Daí a necessidade da arte e, mais especificamente, da literatura como testemunho de uma época afirmava-se como histórica: "the essence of the testimony is historical, and its functions is to record events and to report the facts of a historical occurrence" (FELMAN, 1992, p. 8). Modificam-se os tradicionais laços que ligam a história à narrativa e é cada vez mais forte a exigência histórica de introduzir na literatura a "ação", tentando criar uma narrativa como depoimento, não apenas para "lembrar" mas acima de tudo para "repensar", ultrapassando o mero acontecimento histórico através de um testemunho literário:

Joining events to language, the narrator-as-eyewitness is the testimonial bridge which, mediating between narrative and history, guarantees their correspondence and adherence to each other. This bridging between narrative and history is possible since the narrator is both an informed and 
an honest witness ['témoinfidèle']. Once endowed with language through te medium of the witness, bistory speaks for itself. (FELMAN, 1992,p. 101).

Os autores, portanto, sentem a exigência de referir directamente os eventos - a história - que eles mesmo viveram, reflectindo sobre os fatos e apontando para uma mais profunda preocupação histórica e política.

Nas condições do regime fascista em Itália, o Neorrealismo reconsiderou os grandes conflitos sociais e políticos da época e foi um ponto de encontro da parte mais válida da intelectualidade progressista e democrática italiana. Foi levantada a "tampa" das censuras, aplicadas pelo velho regime, e apareceu a verdadeira condição da Itália: atraso, exploração, fome, violência, ignorância.

A descoberta da "Itália real", ocultada pelo fascismo, em antítese à propaganda do regime, a crítica à burguesia contraposta à solidariedade com o mundo popular, a desilusão da guerra imposta pelo fascismo, a ocupação alemã, os episódios dos campos de concentração, a Resistência, o nascimento da Republica, o início da guerra fria, os novos conflitos sociais, a intensificação da Questione Meridionale foram alguns dos motivos típicos da narrativa neorrealista.

Tudo mudou a partir de 1943, ano da primeira queda de Mussolini, as línguas "cortadas" voltaram a emitir sons, finalmente livres de falar como queriam: linguagens sóbrias, fatos documentados, simplicidade de ideias, histórias verdadeiras quase sempre trágicas, documentos de vida, muitas vezes terríveis; tudo o que o fascismo tinha proibido para não "sujar" a magnifica visão que ele mesmo tinha divulgado no mundo para impressionar amigos e rivais.

À prioridade das palavras foi substituída a prioridade dos fatos. E, se no ventennio fascista tinha triunfado a cultura "central de Roma", tão apadrinhada pelo mesmo Duce, agora parecia urgente uma viagem, do centro até as periferias do país, que compreendesse a realidade "barbárica" do Sul da Itália, a voz ofendida do povo, o ressentimento do campo, em luta perene contra o 
latifúndio ou do Norte camponês ou operário que, com a Resistenza,tinha combatido nas montanhas contra os fascistas.

Debruçando-se sobre as suas próprias vivências, denunciando os males sociais da sua terra, preconizava-se assim a regionalização dos temas literários. No plano formal, procurava-se uma viva pesquisa da oralidade e de uma reprodução da linguagem falada: sintaxe simples, léxico regional. Entrava, desta forma, na literatura, o povo italiano que falava o dialecto e que se enganava falando a língua nacional, mas que era portador de conhecimento inédito para divulgar.

Pela primeira vez, depois de um longo silêncio, o Neorrealismo, através dos seus escritores - de coisas e não de palavras - dava a voz a grupos sociais que não ousavam ou não sabiam dizer o que realmente pensavam. Por estas razões, Italo Calvino, na célebre introdução ao seu romance $I l$ sentiero dei nidi di ragno dedicado à Resistenza, discutindo as origens e os conteúdos do Neorrealismo, falou da explosão literária daqueles anos, como uma necessidade coletiva de um povo que, oprimido durante vinte anos, sentia finalmente a exigência de se expressar livremente:

La rinata libertà di parlare fu per la gente al principio smania di raccontare: nei treni che riprendevano a funzionare, gremiti di persone e pacchi di farina e bidoni d'olio, ogni passeggero raccontava agli sconosciuti le vicissitudini che gli erano occorse, e così ogni avventore ai tavoli delle 'mense del popolo', ogni donna nelle code ai negozi; il grigiore delle vite quotidiane sembrava cosa d'altre epoche; ci muovevamo in un multicolore universo di storie. (CALVINO, 1964, VII).

Da mesma opinião é a escritora Natalia Ginzburg que fala de uma "vindima de palavras":

nel tempo del fascismo, i poeti s'erano trovati ad esprimere solo il mondo arido, chiuso e sibillino dei sogni. Ora c'erano di nuovo molte parole in circolazione, e la realtà di nuovo appariva a portata di mano; perciò quegli antichi digiunatori si diedero a vendemmiarvi com delizia. 


\section{Gaspare Trapani}

E la vendemmia fu generale, perché tutti ebbero l'idea di prendervi parte... (GINZBURG, 1967, X).

O Neorrealismo, portanto, traduz, em forma literária ou cinematográfica, uma mudança registada na sociedade italiana, depois da queda do regime de Mussolini. De resto também os maiores políticos antifascistas da época, evidenciaram, nos seus discursos na Itália desoprimida, a reconquistada liberdade:

Il cittadino italiano, per 20 anni era diventato una figura, un semplice numero della grande massa. Era completamente inutile che esso avesse un'opinione. Noi, rovesciato il fascismo, abbiamo ridato ad ogni singolo cittadino una personalità umana. Era fatale de nostro movimento antifascista che passassimo, direi, al di là della línea media... e dicessimo: tu dì com tue parole, poiché si tratta... del tuo destino... oggi devi imparare ad avere un'opinione tua...(DE GASPERI, 1956, p. 233).

Apareceram, assim, obras literárias e cinematográficas que informavam, através das suas histórias, como se vivia, se pensava, se falava efetivamente, num país, cujo regime tinha escolhido o melhor italiano e uma literatura de evasão, para esconder a sua situação trágica e, por vezes, ridícula. O Neorrealismo, mesmo por estas razões, não foi uma escola, nem teve um manifesto; foi quase um estado da alma, um vasto movimento de ideias, com componentes híbridas e indistintas, caracterizado por personalidades e experiências diferentes, mas sempre numa óptica essencialmente humanista:

Fu un insieme di voci, in gran parte periferiche, una molteplice scoperta delle diverse Italie, anche - o specialmente - delle Italie fino allora più inedite per la letteratura. Senza la varietà di Italie sconosciute l'una all'altra - o che si supponevano sconosciute, - senza la varietà dei dialetti e dei gerghi da far lievitare e impastare nella lingua letteraria, non ci sarebbe stato 'neorealismo' (CALVINO, 1964, IX).

A vivacidade da polemica, no entanto, não impediu a intelectuais de diferentes opiniões a convergência em objetivos fundamentais. Não parece, contudo, possívellimitar o Neorealismo a uma simples questão de poéticas ou 


\section{Gaspare Trapani}

escolas, porque nele foram elaboradas experiências que ultrapassavam a fronteira rigidamente literária, para investir a situação do homem e do intelectual e, conjuntamente, o futuro social e político do cidadão. Desta forma, o Neorrealismo alimentava-se de uma consciência e de uma responsabilidade que atribuíam à arte, e mais em geral à cultura, um empenhamento claro que tinha como objetivo a radical promoção ética do indivíduo e da comunidade, através da sua forte ligação com a representação direta da realidade.

\section{Referência bbliográfica}

AA.VV. Aula IV. Tutti i processi del Tribunale speciale fascista. Roma: Anppia, 1961.

AZEVEDO, Manuel de. O cinema italiano do após-guerra e o neo-realismo.

Coimbra: Contraponto, 1955.

BO, Carlo. "Il neorealismo trent'anni dopo", in Lettere Italiane.

Padova/Firenze: Leo S. Olschki, 1975. N. ${ }^{\circ}$ 4, Outubro-Dezembro, p. 396409.

BOBBIO, Norber. Fascismo e società italiana. Torino: Einaudi, 1973.

BORSELLINO, Nin. Pirandello, la guerra e il fascismo. In: Ritratto e immagini di Pirandello. Roma e Bari, 1991. p. 60-74.

CALVINO, Italo. "Smania di raccontare e neorealismo", introdução. In: Il sentiero dei nidi di ragno. Milano: Mondadori, 1964. p. V-XI, 
CARLI, Mario; FANELLI, Giuseppe Attilio, Antologia degli scrittori fascisti. Firenze: Bemporad, 1931.

CAROCCI, Giampiero. Storia d'Italia dall'Unità ad oggi. Milano: Feltrinelli, 1998.

CORTI, Maria. Il viaggio testuale. Torino: Einaudi, 1978.

DE FELICE, Renzo. Autobiografia del fascismo, antologia di testi fascisti 1919-1945. Bergamo: Minerva Italica, 1978.

DE GASPERI, Alcide. Discorsi Politici. Roma: Edizioni Cinque Lune, 1956.

FALASCHI, Giovanni. Realtà e retorica. La letteratura del neorealismo italiano. Messina-Firenze: G. D’Anna, 1977.

FELMAN, Shoshana. Testimony: Crises of Witnessing in Literature, Psychoanalysis and History. London: Routledge, 1992.

GINZBURG, Natalia. La vendemmia di parole. In: Lessico Familiare. Torino: Einaudi, 1967. p. VI-XII.

GOBETTI, Piero. Rivolurione Liberale. 1922. I, n.34. . Scritti politici. Torino: Einaudi, 1960.

GRAMSCI, Antonio. Letteratura e Vita Nazionale. Torino: Einaudi, 1954. 
GRAMSCI, Antonio. Quaderni dal carcere. Torino: Einaudi, 1975. . A formação dos intelectuais. Amadora: Fronteira, 1976.

HAMILTON, Alastair. L'illusione fascista. Milano: Mursia, 1972.

LUKÁKS, Giorgy. Il Marxismo e la critica letteraria. Torino: Einaudi, 1964.

LUTI, Giorgio. Cronache letterarie tra le due guerre (1920-1940). Bari: Laterza, 1966.

LUTI, Giorgio. La letteratura nel ventennio fascista. In: Libri senza moschetto. Riviste e periodici, monografie e opuscoli di cultura e propagande del Ventennio. Furenze: La Nuova Italia, 1995.

MARX, Karl; ENGELS, Friedrich. Scritti sull'arte. Bari: Laterza, 1967.

MARX, Leo; MAZLISH, Bruce. Progresso: realidade ou ilusão?. Lisboa: Bisâncio, 2001.

MONTALE, Eugenio. Auto da fé. Milano: Il Saggiatore, 1966.

MUSSOLINI, Benito. Scritti e Discorsi. Milano: Hoepli, 1934.

PASOLINI, Pier Paolo. Scritti Corsari. Milano: Garzanti, 1975.

PAVESE, Cesare. Saggi letterari. Torino: Einaudi, 1951. 
PINTOR, Giaime. Il sangue d'Europa (1939-1943). Torino: Einaudi, 1965.

RONDI, Brunello. Il Neorealismo Italiano. Parma: Guanda, 1956.

SALVEMINI, Gaetano. La nuova libertà. In: GIUDICE, Aldo; BRUNI Giovanni. Problemi e scrittori della letteratura italiana. Torino: Paravia, 1988. Vol. 3, Tomo 2, p. 476-479.

SARTRE, Jean-Paul. O escritor não épolitico?. Lisboa: Dom Quixote, 1971.

SCARPELLINI, Emanuela. Un palcoscenico per Mussolini. In: Corriere della Sera. 2006. 11 de Janeiro, p. 27. 